\title{
The Newest Developments of Load-Unload Response Ratio (LURR)
}

\author{
Xiang-Chu Yin, ${ }^{1,2}$ Lang-Ping Zhang, ${ }^{2}$ Yongxian Zhang, ${ }^{2,3}$ Keyin Peng, ${ }^{2,3}$ \\ Haitao Wang, ${ }^{2,5}$ Zhiping Song, ${ }^{2,6}$ Huaizhong Yu, ${ }^{2}$ Hui-Hui Zhang, ${ }^{4}$ Can Yin, ${ }^{7}$ and \\ YUCANG WANG ${ }^{2,7}$
}

\begin{abstract}
The Load Unload Response Ratio (LURR) method is an intermediate-term earthquake prediction approach that has shown considerable promise. It is inspiring that its predictions using LURR have been improving. Since 2004 we have made a major breakthrough in intermediate-term earthquake forecasting of the strong earthquakes on the Chinese mainland using LURR and successfully predicted the Pakistan earthquake with magnitude M 7.6 on October 8, 2005. The causes for improving the prediction in terms of LURR have been discussed in the present paper.
\end{abstract}

Key words: LURR (Load Unload Response Ratio), earthquake prediction, Chinese mainland, M 7.6 Pakistan earthquake.

\section{Introduction}

An earthquake is a very complicated phenomenon. The essence of an earthquake, from the viewpoint of mechanics or physics, is precisely the failure or instability of the focal media accompanied by a rapid release of energy. Therefore the preparation process of an earthquake is exactly the damage process of the focal media.

From the microscopic viewpoint, the damage process of geo-material has incredible richness in complexity. In any rock block there must be a large number of disordered defects (cracks, fissures, joints, faults and caves) with different sizes, shapes and orientations. The damage process of the focal media includes initiation, growth,

\footnotetext{
${ }^{1}$ Institute of Earthquake Science, China Earthquake Administration (CEA), Beijing 100036, China. Email: xcyin@public.bta.net.cn

${ }^{2}$ LNM (State Key Laboratory of Nonlinear Mechanics), Institute of Mechanics, Chinese Academy of Sciences (CAS), Beijing 100190, China.

3 China Earthquake Network Center, CEA, Beijing 100036, China.

${ }^{4}$ School of Civil Engineering and Mechanics, Yanshan University, Qinhuangdao 066004, China.

5 Xinjiang Earthquake Bureau, CEA, Urumchi 830011, China. Emails: whtxj@xj.cninfo.net

6 Shanghai Earthquake Bureau, CEA, Shanghai 200062, China. Emails: zpsong@sohu.com

7 ESSCC, University of Queensland, Australia, the University of Queensland, St. Lucia, Brisbane QLD 4072, Australia. Email: wangyc@esscc.earth.uq.edu.au
} 


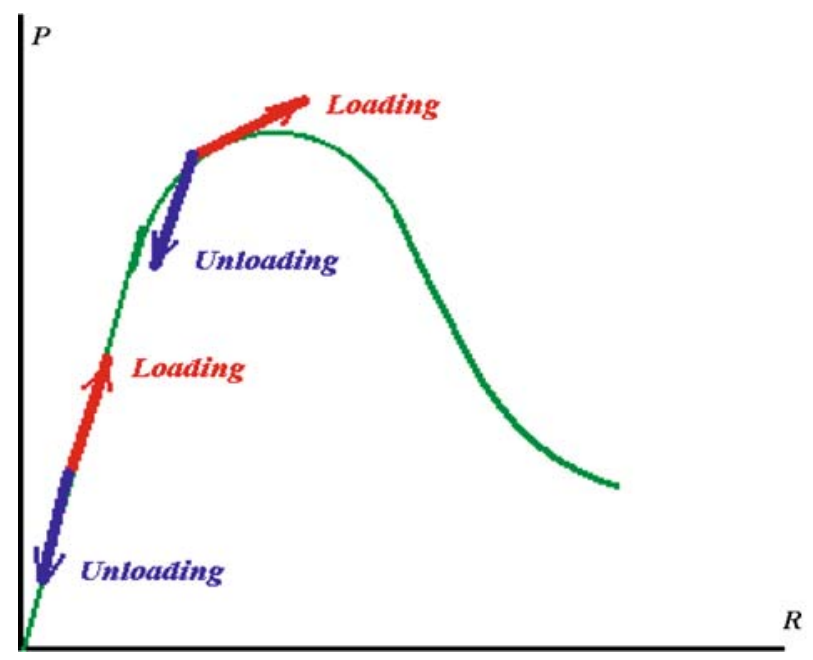

Figure 1

The constitutive curve of a focal zone.

interaction, coalition and cascade of cracks. It is an irreversible, far-from-equilibrium and nonlinear process which has been intensively studied for nearly half century; however numerous fundamental questions still remain unsolved. The inherent difficulty of earthquake prediction stems mainly from this complexity.

From the macroscopic viewpoint the constitutive relation is a comprehensive description of the mechanical behaviors of the materials. A typical constitutive relation for focal media (rock) is shown in Figure 1. We define a more general coordinate system where the general load $P$ is used instead of stress $\sigma$ and the general response $R$ to load is used instead of strain $\varepsilon$ in Figure 1. If the load acting on a specimen increases monotonously, the specimen will experience the regimes of elastic, damage and failure or destabilization. The most essential characteristic of the elastic regime is its reversibility, i.e., the loading modulus and the unloading one are equal to each other. Contrary to the elastic regime, the damage one is irreversible and the unloading response is different from the loading one, or the loading modulus is different from the unloading one. This difference indicates the deterioration of material due to damage. In terms of seismology, this difference reflects quantitatively the process of an earthquake preparation.

A physics-based new parameter-Load-Unload Response Ratio (LURR) was proposed to measure quantitatively the proximity to a strong earthquake and then used to be an earthquake predictor. It involves calculating the ratio of a specified energy release measure during loading and unloading where loading and unloading periods are determined from the earth tide induced perturbations in the CFS (Coulomb Failure Stress) on optimally oriented faults. In the lead-up to large earthquakes, high LURR values are frequently observed a few months or years prior to a strong earthquake. To date the 
LURR method is mainly applied for intermediate-term earthquake prediction. We have predicted some strong events successfully using the LURR approach, with few false predictions, especially in the early stage.

\section{The Newest Developments of LURR}

It is inspiring that the prediction results using LURR have been continuously improving. Since 2004, we have made a major breakthrough in intermediate-term earthquake forecasting in terms of LURR. Figure 2 shows the anomalous LURR regions in the Chinese mainland, calculated at the end of 2003, namely the regions where the LURR value is equal to or larger than 1 and marked with color.

In fact, the real area of the seismogenic region should be larger than the anomalous LURR regions (color regions). If $\mathrm{P}$ is a point at the boundary of the anomalous LURR regions. This means that the LURR value $Y$ in the special window (a circle region centered at $\mathrm{P}$ with radius $\mathrm{R}$ ) is equal to or larger than 1 and is assigned the $Y$ value at point $\mathrm{P}$ (Fig. 4). In other words, the whole circle region centered at $\mathrm{P}$ with radius $\mathrm{R}$ is in a seismogenic state. At every point of the boundary of LURR anomalous regions we can draw a circle with radius $\mathrm{R}$, and then an envelope of all the circles can be drawn. The areas in the envelope should be the seismogenic regions. We predicted that there would be a high probability of occurrence for $M_{s} \geq 5$ earthquakes in the next year (2004) in

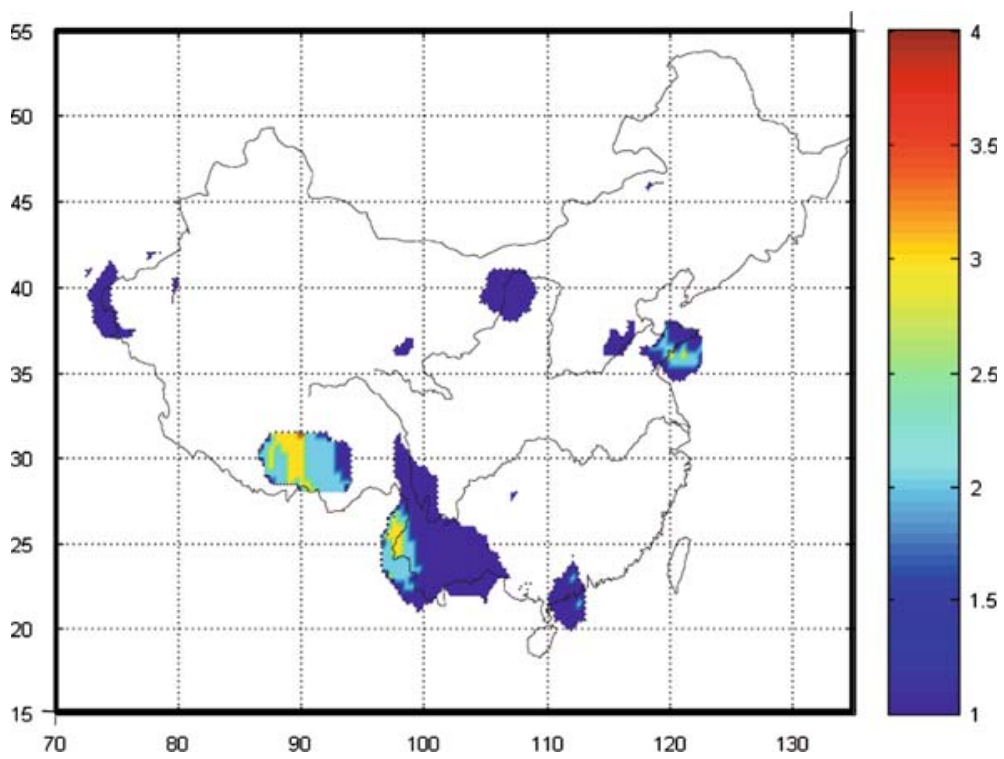

Figure 2

The anomalous LURR regions in the Chinese mainland calculated at the end of 2003 will have a high probability of occurrence for earthquakes with $M \geq 5$ in the next year (2004). 


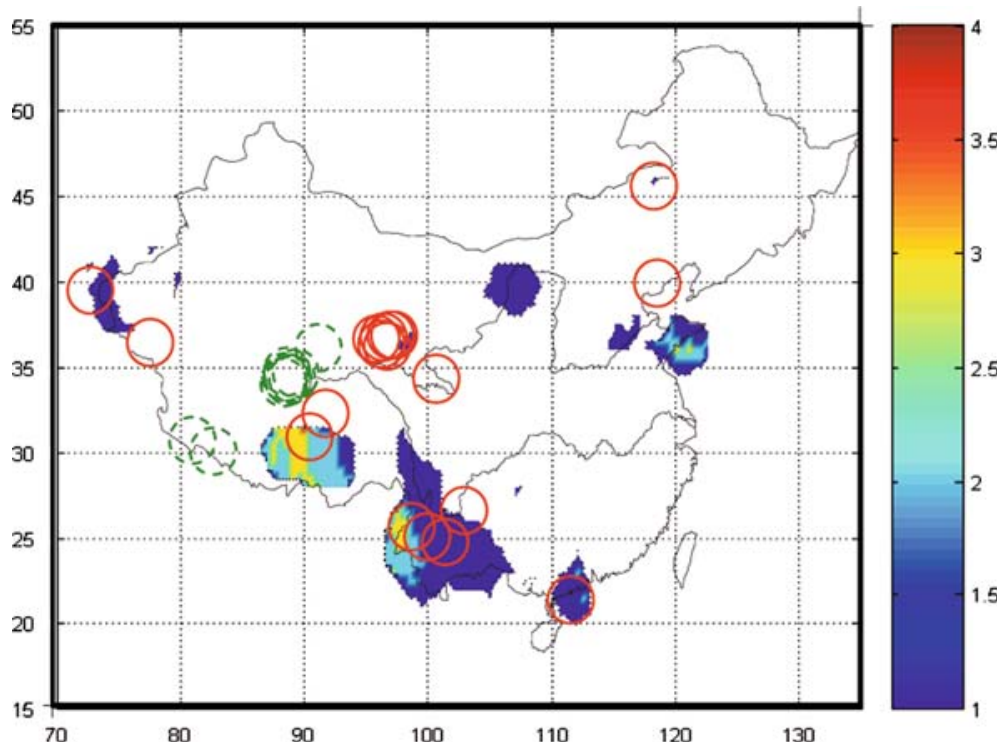

Figure 3

The map of epicenters of earthquakes with magnitude $M_{s} \geq 5$ in 2004 in the Chinese mainland. The red solid circles denote the events which occurred in regions in which the observed data are good enough to calculate LURR, and the green dashed circles denote the events which occurred in regions where the scarcity of observed data make the LURR calculation impossible.

these seismogenic regions. This result was issued in the book The Research on Seismic Tendency of China in 2004, edited by the Center for Analysis and Prediction, CSB, pp. 282-285 (YIN et al., 2003) which was officially published in the end of 2003 by

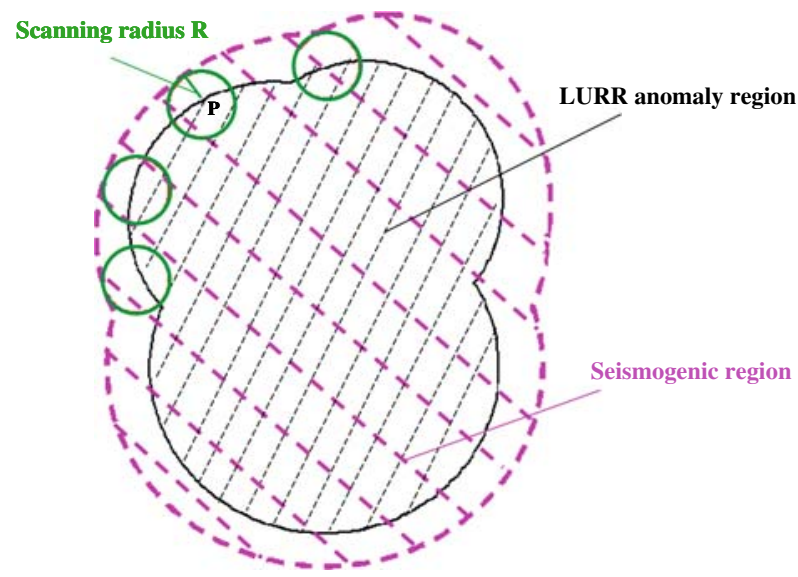

Figure 4

The sketch of an LURR anomaly region and a seismogenic region. 
Seismological Press, Beijing. Figure 3 shows epicenters of earthquakes with magnitude $M_{\mathrm{s}} \geq 5$ which occurred in the Chinese mainland in 2004. The red solid circles denote the events of $M_{s} \geq 5$ (total number 17) which occurred in the regions in which the observed data are available to calculate LURR, and the green dashed circles denote the events of $M_{s} \geq 5$ (total number 16) which occurred in regions such as Tibet, where the observed data are not available to calculate LURR. According to the standard of the Chinese seismological circle, the earthquakes which occurred in the data scarcity regions should be ignored statistically. If an earthquake occurred in the seismogenic regions, namely if an earthquake occurred in the anomalous LURR regions or its epicenter distance from the anomalous LURR regions is less than the radius of the spatial window, this event is considered a successfully predicted one. Figure 3 shows us that there are 15 events among 17 (a percentage of 88\%) which occurred in the predicted LURR anomalous regions.

In 2005 the predicted result in terms of LURR was even better than 2004 (YIN et al., 2004). There were twelve strong earthquakes with $\mathrm{M}_{\mathrm{s}} \geq 5$ among total 13 earthquakes ( $a$ percentage of 92\%) which occurred in the seismogenic regions. The only missing forecasted one-Jiujiang earthquake (Jiangxi Province in eastern China) with magnitude M 5.7 (November 26,$2005 ; 29.7^{\circ} \mathrm{N}, 115.7^{\circ} \mathrm{E}$ ) is not in the LURR anomalous regions, but is located in the data scarcity regions (Fig. 5). Noting that the minimum value of the color bar (color key) in Figure 5 is 0 instead of 1.0 in Figures 2 and 3. Therefore all the blank areas (uncolored) in Figure 5 are the areas in which the observed data are not available to calculate LURR.

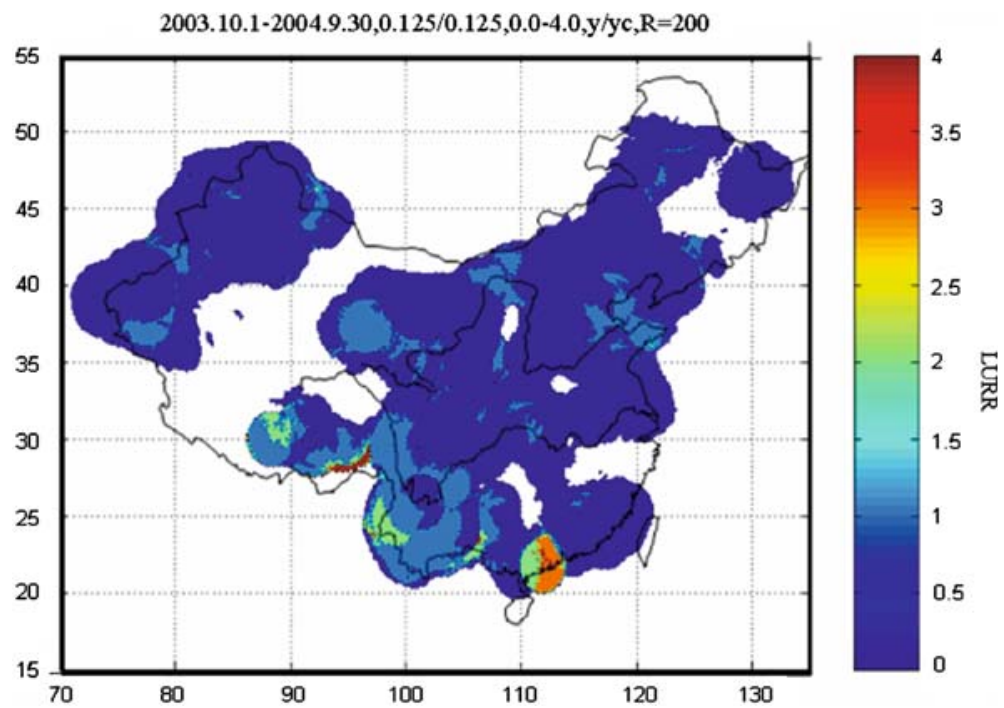

Figure 5

The definition of a data scarcity region. All the blank areas are data scarcity regions. 


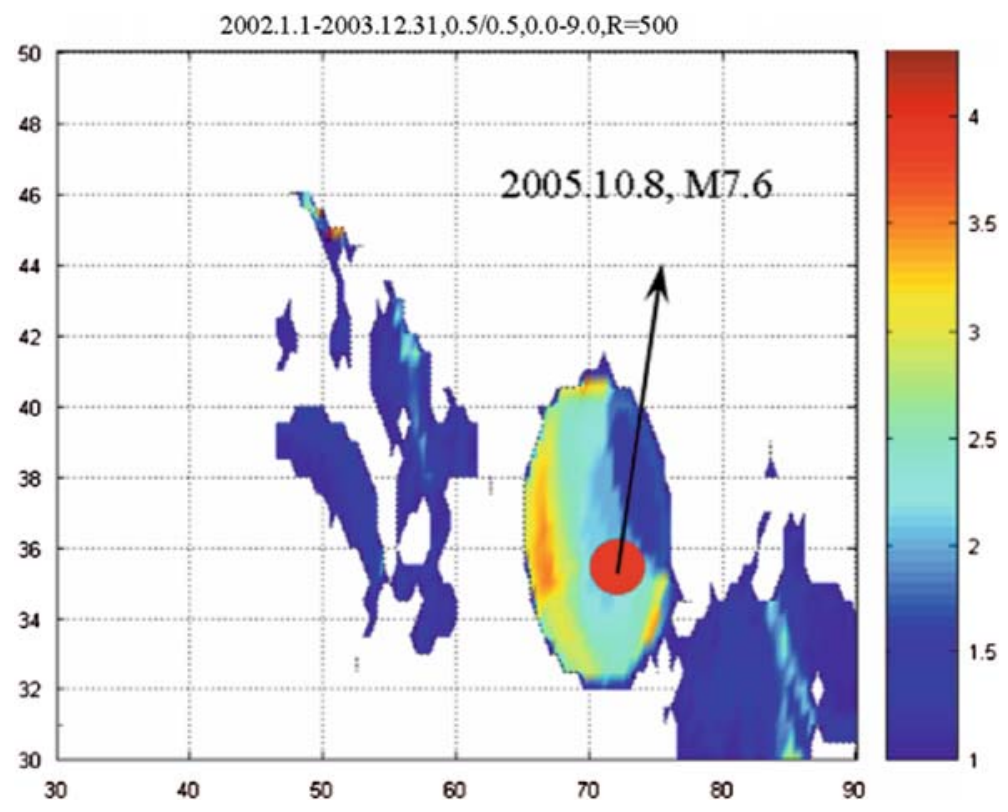

Figure 6

A spatial scanning of LURR in the Europe-Asia seismic belt during the period from 2002.1.1 to 2003.12.31.

The prediction of the Pakistan earthquake with a magnitude of M 7.6 on October 8, 2005 deserves particular mention here. The LURR special scanning of the Euro-Asian seismic belt $\left(30^{\circ}-50^{\circ} \mathrm{N}, 30^{\circ}-90^{\circ} \mathrm{E}\right)$ was conducted in 2003 . The outcomes (Fig. 6) were issued in the Journal Mechanics in Engineering (YIN, 2004) and Supercomputing Newsletter, sponsored by the Computer Network Information Center, Chinese Academy of Sciences. The Pakistan earthquake which occurred on October 8, 2005 was exactly sited fallen in the high LURR region.

It is also worth mentioning the prediction of the Yangjiang (Guangdong Province in southern China) earthquake with a magnitude of $\mathrm{M}_{\mathrm{s}} 5$ on October 17, 2004. We conducted a LURR spatial scanning of the Chinese mainland on the super-computer DeepComp 6800 in the Supercomputing Center of Computer Network information Center, Chinese Academy of Science on September 1, 2004 (Fig. 7). It is obvious that of all the abnormal areas the Yangjiang region was the most remarkable. Based on this result, we predicted that an earthquake of approximately M 5 would occur very soon in this region. We issued our prediction at the DeepComp 6800 User Workshop on 11 September, 2004. Just six days following the Workshop, the Yangjiang region was hit by an M 5 earthquake. This case suggested that LURR probably has the potential ability for short-term earthquake prediction. 


\section{Discussion}

As mentioned above the prediction results of LURR have been continuously improving in recent years. According to our understanding, the reasons for the improvement comprise the following aspects:

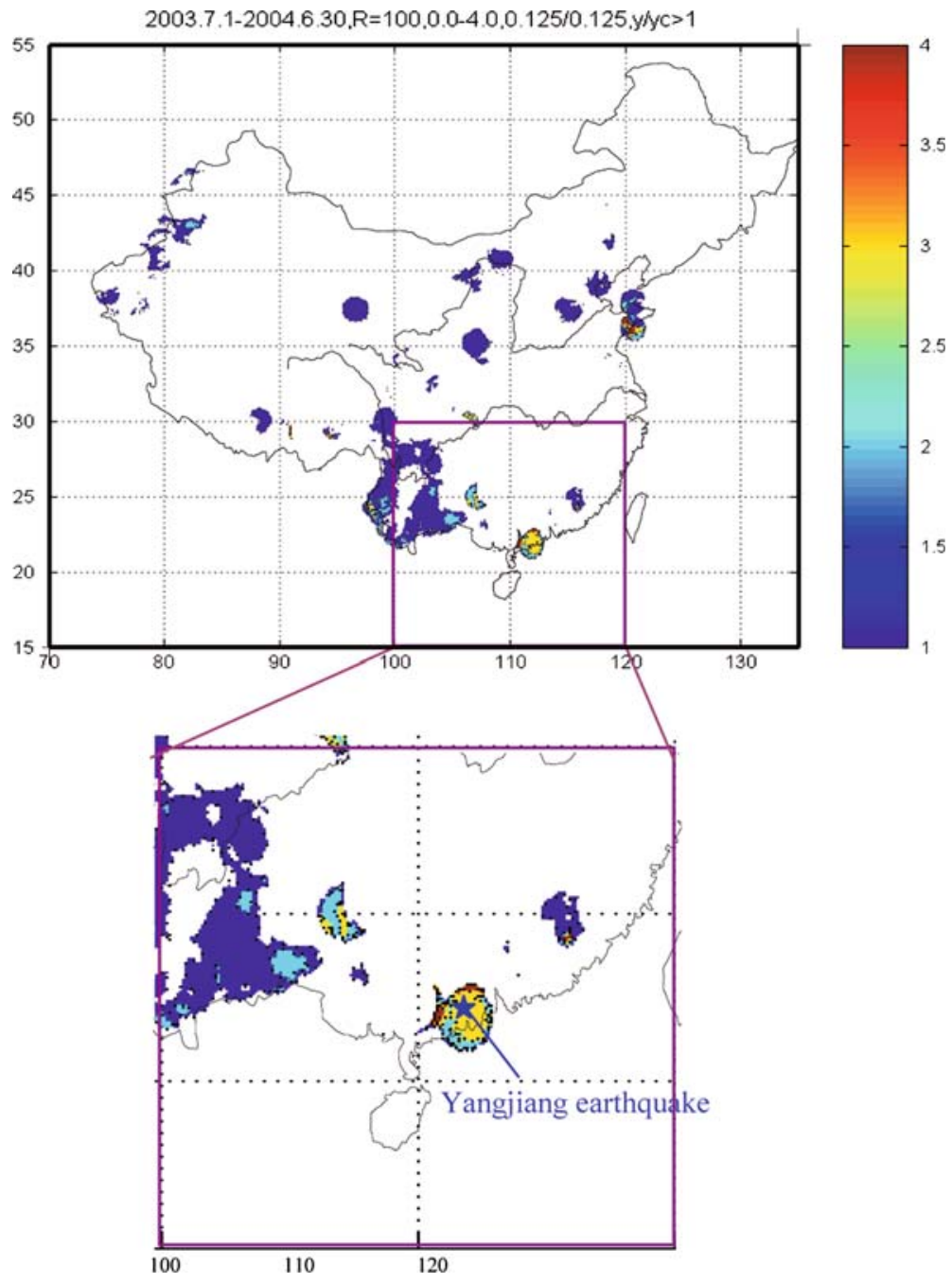

Figure 7

Spatial scan of mainland China on September 1, 2004, we predicted a magnitude 5 earthquake would soon hit the Yangjiang region of the Guangdong province in southern China. Such an event occurred within a month of our prediction. 


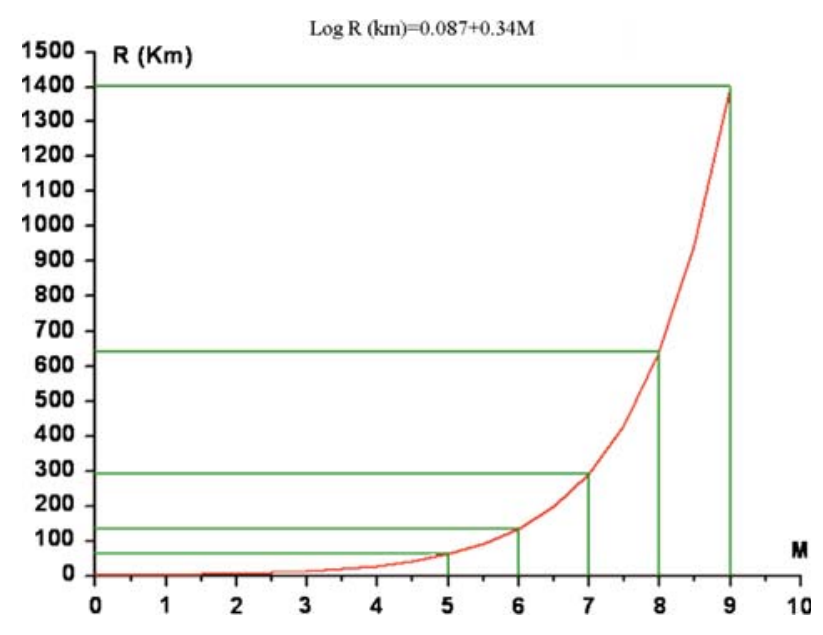

Figure 8

The scaling relation between $\mathrm{R}$ (the radius of a circular spatial window) and $\mathrm{M}$ (the magnitude of a predicted forthcoming earthquake).

\subsection{Proper Scaling}

Any physical problem has its scaling relation. It is very important to select proper temporal and spatial windows in researching any physical problem. We determined the scales of temporal and spatial windows according to our previous experience and now they are determined by the scaling laws shown in Figure 8 (YIN et al., 2002; PENG et al., 2006) for the spatial window and Figure 9 (Zhang et al., 2005; ZHANG, 2006) for the temporal window.

Fourteen earthquakes that occurred in China have been studied with magnitudes ranging from 5.1 to 8.1 (PENG et al., 2006). It is found that the critical region size scales with the magnitude of the earthquake. Fitting the data, the function between critical region size and the magnitude is

$$
\log R(\mathrm{~km})=0.087+0.34 M
$$

Figure 8 shows the function above in a more direct way.

Figure 9 shows the definitions of seismogenic duration. $T$ is the total seismogenic duration which denotes the period from the beginning of the LURR anomaly (LURR $\geq 1$ ) to the occurrence of a strong earthquake, $T_{2}$ is the period from the peak point of LURR to the occurrence time and $T_{1}$ is from the beginning of LURR to the peak point. Obviously

$$
T=T_{1}+T_{2}
$$




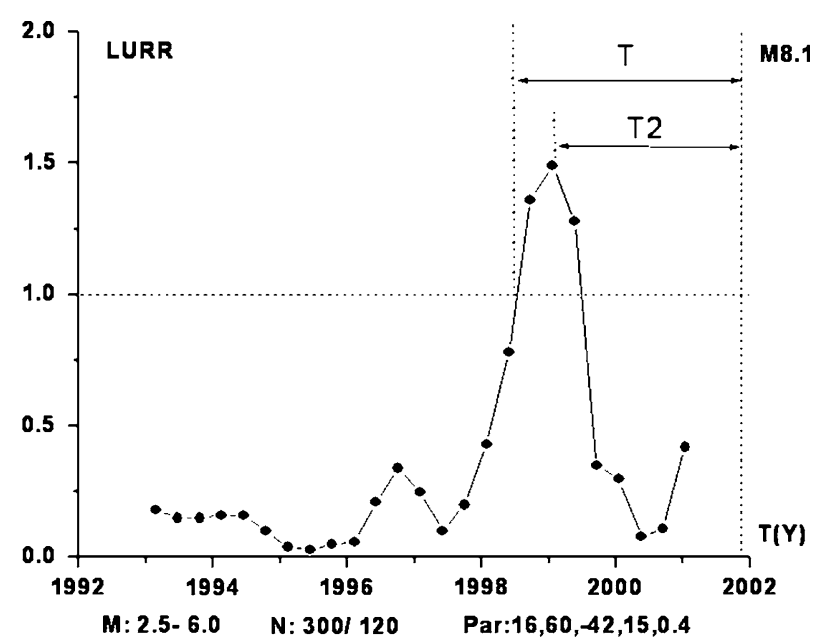

Figure 9

The definitions of seismogenic duration (measured in the month) using a large earthquake with $\mathrm{M}=8.1$ (Nov. $14,2001)$ as an example. $T$ denotes the total seismogenic duration, $T_{2}$ denotes the duration from the peak point of LURR to the occurrence time of the earthquake and $T=T_{1}+T_{2}$.

According to our recent study, the peak point of LURR implies the nucleation of the earthquake. Therefore $T_{2}$ is the nucleation period which has such manner of function as below (YiN and ZHENG, 1983; Zheng and YiN, 1984; OHNAKA, 2004),

$$
\Delta T=A\left(1-B \times 10^{-C M}\right),
$$

where $\Delta T$ denotes the nucleation period, $M$ is the magnitude of earthquake and $A, B, C$ are material constants. According to the data of 30 earthquakes with magnitudes ranging from 5.0 to 8.1 which occurred in the Chinese mainland, we obtained

$$
T=80\left(1-2.5 \times 10^{-0.09 M}\right)
$$

and

$$
T_{2}=60\left(1-2.3 \times 10^{-0.08 M}\right)
$$

where the time is measured in month. Figure 10 shows the function of $\mathrm{T}$ and the broken lines defines the error bar.

\subsection{Better Parameters Selection}

In order to calculate LURR, many parameters are required, such as fault mechanism, depth etc. In order to felicitously select these parameters we have been searching for references from considerable literatures, accumulating experience and conducting the scanning in parameter space according to MFO proposed by Can YIN (YIN, 2005). 


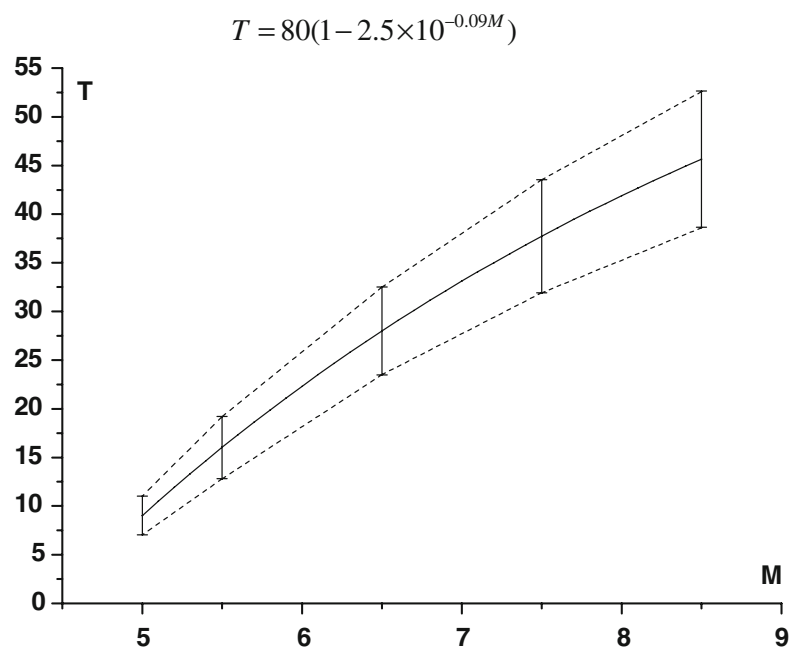

Figure 10

The scaling relation between $\mathrm{T}$ (the temporal window measured in the month) and $\mathrm{M}$ (the magnitude of a predicted forthcoming earthquake). The broken lines define the error bar.

\subsection{Supercomputing}

All the works above, especially MFO, need supercomputing. We conducted most of the computing in the Supercomputing Center of Computer Network Information Center, Chinese Academy of Sciences (CAS).

\subsection{Earthquake Physics}

The last, nonetheless the most important issue, is the deep understanding of the earthquake physics through basic research (RUNDLE et al., 2000; MoRA et al., 2002; WANG et al., 2002; SAmmis and SornetTe, 2002; XIA et al., 2002; WANG et al., 2004; YIN, 2005; Yin et al., 2004; Yu, 2004; ZHANG et al., 2005; Rong et al., 2006; ZHANG, 2005; Yin et al., 2006; Y In, Mora et al., 2006). Any deeper advance into earthquake physics within, enhances LURR.

\section{Acknowledgement}

The authors gratefully acknowledge the support from MOST under Grant No.2004 CB418406, NSFC under Grant No.10572140, the Informalization Construction of Knowledge Innovation Projects of the Chinese Academy of Sciences "Supercomputing Environment Construction and Application" (INF105-SCE-2-02). 


\section{REFERENCES}

Mora, P., Wang, Y., Yin, C., Place, D., and Yin, X.C. (2002), Simulation of Load-Unload Response Ratio and critical sensitivity in the lattice solid model, Pure Appl. Geophys. 159, 2525-2536.

Онnака, M. (2004), A Constitutive scaling law for shear rupture that is inherently scale-dependent, and physical scaling of nucleation time to critical point, Pure Appl. Geophys. 161, 1915-1929.

Peng, P., Yin, X.C., and Zhang, L.P. (2006), A statistical investigation of the earthquake predictions using LURR, Pure Appl. Geophys. 163, 2353-2362.

Rong, F. (2006), Multiscale Simulation of Damage Evolution in Heterogeneous Brittle Media, Ph.D. Thesis, the Graduate School, Chinese Academy of Sciences.

Rundle, J.B. et al., (2000), Precursor seismic activation and critical-point phenomena, Pure Appl. Geophys. 157, 2165-2182.

SAmmis, C.G. and Sornette, D. (2002), Positive feedback, memory, and the predictability of earthquakes, PNAS 99, 2501-2508.

WANG, Y.C., Yin, X.C., KE, F.J., XIA, M.F., and PENG, K.Y. (2000), Simulation of rock failure and earthquake process on mesoscopic scale, Pure Appl. Geophys. 157, 1905-1928.

WANG, Y.C., Mora, P., Y IN, C., and Place, D. (2004), Statistical tests of Load-Unload Response Ratio signals by lattice solid model: Implication to tidal triggering and earthquake prediction, Pure Appl. Geophys. 161, 1829-1839.

XIA, M.F., WEI, Y.J., Ke, F.J., and BAI, Y.L. (2002) Critical sensitivity and transscale fluctuations in catastrophe rupture, Pure Appl. Geophys. 159, 2491-2509.

XIANG-CHU YIN and ZHENG TIAN-YU (1983), A rheological model for the process of preparation of an earthquake, Scientia Sinica 26, 285-296.

YIN, C. (2005), Exploring the underlying mechanism of Load/Unload Response Ratio theory and its application to earthquake prediction, Ph.D. Thesis, The University of Queensland, Australia.

YIN, X.C. and YIN, C. (1991), The precursor of instability for nonlinear system and its application to earthquake prediction, Science in China 34, 977-986.

YIN, X.C. (1993), A new approach to earthquake prediction, Природа (Russia's "Nature”) 1, 21-27 (in Russian).

YIN, X.C., YIN, C., and Chen, X.Z. (1994), The precursor of instability for nonlinear system and its application to earthquake prediction-The Load-Unload Response Ratio theory. In Nonlinear Dynamics and Predictability of Geophysical Phenomena (eds. Newman, W.I., Gabrelov, A., and Turcotte, D.L.), Geophysical Monograph 83, IUGG Volume 18, 55-60.

Yin, X.C., Chen, X.Z., Song, Z.P., and Yin, C. (1995), A new approach to earthquake prediction: The Load/ Unload Response Ratio (LURR) theory, Pure Appl. Geophys. 145, 701-715.

Yin, X.C., Wang, Y.C., Peng, K.Y., BaI, Y.L., Wang, H.T., and Yin, X.F. (2000), Development of a new approach to earthquake prediction-Load/Unload Response Ratio (LURR) theory, Pure Appl. Geophys. 157, 2365-2383.

Yin, X.C., Mora, P., Peng, K.Y., Wang, Y.C., and Weatherly, D. (2002), Load-Unload Response Ratio and accelerating moment/energy release, critical region scaling and earthquake prediction, Pure Appl. Geophys. 159, 2511-2524.

Yin, X.C., Peng, K.Y., Yu, H.Z., WANG, Y.C., Yin, C., and Zhang, Y.X. (2002), Scaling of LURR critical region, $3^{\text {rd }}$ ACES Workshop, May 5-10, 2002, Island of Maui, Hawaii, U.S.A.

Yin, X.C., Zhang, H.H., Yu, H.Z., Zhang, Y.X., and Peng, K.Y. (2003), Prediction of seismic tendency of Chinese mainland in 2004 in terms of LURR. In The Research on Seismic Tendency of China in 2004, (ed. Center for Analysis and Prediction, CSB), pp 282-285, Seismological Press, Beijing, 2003 (in Chinese).

Yin, X.C., Zhang, H.H., Yu, H.Z., Zhang, Y.X., and Peng, K.Y. (2004), Prediction of seismic tendency of Chinese mainland in 2004 in terms of LURR. In The Research on Seismic Tendency of China in 2005, pp. 282-285 (ed. Center for Analysis and Prediction, CSB), Seismological Press, Beijing, 2004 (in Chinese).

Yin, X.C., Yu, H.Z., Kunshenko, V., Xu, Z.Y., Wu, Z.S., Li, M., Peng, K.Y., Elizarov, S., and Li, Q. (2004), Load-Unload Response Ratio (LURR), Accelerating Energy release (AER) and state vector evolution as precursors to failure of rock specimens, Pure Appl. Geophys. 161, 2405-2416. 
YIN, X.C. (2004), A new approach to earthquake prediction-Load/Unload Response Ratio (LURR) theory, Mechanics in Engin. 26, 1-7 (in Chinese).

Yin, X.C., Zhang, L.P., Zhang, H.H., Yin, C., Wang, Y.C., Zhang, Y.X., Peng, K.Y., Wang, H.T., Song, Z.P., Yu, H.Z., and ZhuANG, J.C. (2006), LURR's twenty years and its perspective, Pure Appl. Geophys. 163, 23172341.

Yin, X.C., Mora, P., Donnellan, A., and Matsunra, M. (2006), Introduction to computational earthquake physics, Part I, Pure Appl. Geophys. 163, 1737-1741 and Part II, Pure Appl. Geophys. 163, 2359-2261.

Yu, H.Z. (2004), Experimental Research on Precursors of Brittle Heterogeneous Media and Earthquake Prediction Methods, Ph.D. Thesis, Institute of Mechanics, Chinese Academy of Sciences (in Chinese).

Zhang, H.H., Yin, X.C., and LiAng, N.G. (2005), Statistic study of LURR anomaly temporal scale before moderately strong earthquakes in Chinese mainland, Earthquake Research in China. 21, 486-495.

Zhang, H.H. (2006), Prediction of Catastrophic Failure in Heterogeneous Brittle Media-Study and Practice of Load/Unload Response Ratio (LURR), Ph.D. Thesis, Graduate School, Chinese Academy of Sciences (in Chinese with English abstract which can be found in the National Library of China, Beijing).

Zhang, H.H., Yin, X.C., Liang, N.G., Yu, H.Z., Li, S.Y., Wang, Y.C., Yin, C., Kukshenko, V., Tomiline, N., and Elizarov, S. (2006), Acoustic emission experiments of rock failure under load simulating the hypocenter condition, Pure Appl. Geophys. 163, 2389-2406.

Zhang, X.H., Xu, X.H., XIA, M.F., and BAI, Y.L. (2004), Critical sensitivity in driven nonlinear threshold systems, Pure Appl. Geophys. 161, 1931-1944.

ZHENG TIAN-YU and XIANG-CHU YIN (1984), The subcritical extension of faulting and process of preparation of earthquake, Bull. Sci. China 29, 8, 1081-1086.

(Received September 6, 2006, revised March 30, 2007, accepted April 27, 2007)

To access this journal online:

www.birkhauser.ch/pageoph 